\title{
Electrochemical properties of kenaf-derived activated carbon electrodes under different activation time durations for supercapacitor application
}

\author{
Muhammad Nizam Abdul Razak ${ }^{1}$, Zulkarnain Ahmad Noorden², Farid Nasir Ani', \\ Zulkurnain Abdul-Malek ${ }^{4}$, Jasrul Jamani Jamian ${ }^{5}$, Nouruddeen Bashir ${ }^{6}$ \\ 1,2,4 Institute of High Voltage and High Current, Universiti Teknologi Malaysia, Malaysia \\ ${ }^{3}$ School of Mechanical Engineering, Faculty of Engineering, Universiti Teknologi Malaysia, Malaysia \\ ${ }^{5}$ School of Electrical Engineering, Faculty of Engineering, Universiti Teknologi Malaysia, Malaysia \\ ${ }^{6}$ Power Equipment and Electrical Machinery Development Institute, Nigeria
}

\section{Article Info}

Article history:

Received Dec 13, 2019

Revised Feb 15, 2020

Accepted Feb 29, 2020

Keywords:

Activated carbon

Activation time duration

Electrochemical properties

Kenaf fiber

Supercapacitor

\begin{abstract}
The electrochemical properties of supercapacitors with kenaf-derived activated carbon electrodes under different activation time durations were evaluated. The study aims to determine the optimum activation time required that contributes to highest supercapacitor's perfomance. Kenaf fibre was firstly carbonized at $400{ }^{\circ} \mathrm{C}$ to remove its water content and any volatile substances. The resulted kenaf-derived carbon was then impregnated in potassium hydroxide $(\mathrm{KOH})$ with 4:1 impregnation ratio and left overnight. After the impregnation process, the carbon sample was activated at $600{ }^{\circ} \mathrm{C}$ with different heating time durations of 1,2, 3 and 4 hours and named as A600-1, A600-2, A600-3 and A600-4, repectively. Four supercapacitors with the kenaf-derived activated carbon samples as the electrodes were fabricated based on two-electrode symmetrical test cell system. Specific capacitances of $108,189,242$, and $126 \mathrm{~F} / \mathrm{g}$ for supercapacitors with activated carbon A600-1, A600-2, A600-3 and A600-4 electrodes, respectively were achieved. These were much higher than previously reported values of only up to 37 F/g. The finding suggests that an inexpensive fibrous carbon material derived from kenaf by a facile pyrolysis process may be a remarkable choice to construct high performance supercapacitor.
\end{abstract}

Copyright () 2020 Institute of Advanced Engineering and Science. All rights reserved.

\section{Corresponding Author:}

Zulkarnain Ahmad Noorden,

Institute of High Voltage \& High Current,

Universiti Teknologi Malaysia,

81310 UTM Johor Bahru, Johor, Malaysia.

Email: zulkarnain-an@utm.my

\section{INTRODUCTION}

To meet the power demand in energy storage system and portable (digital) electronic devices supercapacitor can offer a promising alternative approach for this issues [1] since it possesses fast chargedischarging performance, long cyclability and high power density [2, 3]. Based on its charge storage mechanism, supercapacitor can be categorized in two types, namely pseudocapacitor and electric double layer capacitor (EDLC) [4-6]. For a pseudocapacitor, Faradaic reaction takes place during the charge-discharge process where the charges are transferred between electrolyte and electrode material of metal oxides or conduction polymers. Even though pseudocapacitor possesses higher specific capacitance, as compared to an EDLC, it is less favourable capacitor due to its low electrical conductivity, poor cycle stability, and higher price tag $[7,8]$. On the other hand, an EDLC charge mechanism only involves electrostatic charge accumulation onto the electrode-electrolyte interface layer thus providing more stable, faster and superior cycle stability [6]. 
Extensive researches have been carried out on improving the performance of an EDLC's active electrode material, which is made from activated carbon (AC). AC has very high specific area and rich porous structure, leading to its superior specific capacitance [2]. Recently, ACs have been derived from numerous biomass resources such as tea bark[9], aloe vera [6], oil palm shell [10], banana peel [11], corn cob [12], pig skin [13], tea waste [2], flax [14-16], hemp [17, 18], jute [19, 20], kenaf [21-24] due to their advantages such as being environmentally friendly, abundant and cheap. Among these resources, kenaf is known as the most economical resource since it is widely abundant and has short plant-to-harvest period. In addition, during its farming, does not required pest control as it is capable of absorbing heavy metals and chemicals from the soil [25]. This research aims to explore the suitability of kenaf fibre as an electrode material for supercapacitor construction by evaluating the effect of heating time duration on kenaf char soaked in $\mathrm{KOH}$ solution during its activation process.

\section{EXPERIMENTAL}

Raw kenaf fibre was obtained from National Institute of Kenaf and Tobacco, Malaysia. Potassium hydroxide (Vchem, Johchem Scientific \& Instrument Sdn Bhd), Sulphuric acid (Vchem, Johchem Scientific \& Instrument Sdn Bhd), Carbon black (C.nergy super C65, Imerys, Belgium), polyvinylidene fluoride (PVDF) (SigmaAldrich, USA) and 1-Methyl-2-pyrrolidone (NMP), (Sigma-Aldrich, USA) were purchased and used as-received for the experimental work. All measurements were carried out at room temperature condition $\left(25^{\circ} \mathrm{C}-28^{\circ} \mathrm{C}\right)$.

\subsection{Synthesis of kenaf-derived biochar}

The kenaf fibre was dried in an industrial oven (Memmert, Modell 200) at $105{ }^{\circ} \mathrm{C}$ for 24 hours to remove its water content. The kenaf fibre was then grinded and sieved with $2 \mathrm{~mm}$ particle size siever. The carbonization process of the kenaf fibre was carried out to convert its raw form into biochar using a pyrolysis rig which consists of a fixed, vertical bed furnace and a reactor. Firstly, the $25 \mathrm{~g}$ of kenaf fibre was weighed and placed into the vertical reactor. Prior to the pyrolysis process, in order to provide an inert condition in the reactor, nitrogen gas was flowed into the reactor for 5 minutes at $5 \mathrm{~L} / \mathrm{min}$ flow rate. Then, the rate was reduced to a constant flow rate of $1 \mathrm{~L} / \mathrm{min}$. The reactor temperature was then gradually increased at a rate of $10{ }^{\circ} \mathrm{C}$ per minute until a temperature of $400{ }^{\circ} \mathrm{C}$ was reached and maintained for 120 minutes. This process was to remove any volatile substances. Finally, the resulted biochar was cooled down to room temperature under a continuous flow of nitrogen gas.

\subsection{Activation of kenaf-derived biochar}

The as-obtained biochar powder was then activated under a two-step (chemical and thermal) activation process. First, by mixing it with $6 \mathrm{M} \mathrm{KOH}$ with 1:4 (biochar: $\mathrm{KOH}$ ) mass ratio under room temperature condition. The mixture was stirred for 4 hours and then dried at $105{ }^{\circ} \mathrm{C}$ overnight in the industrial oven. The mixture was then heated in the vertical reactor placed in the furnace. The reactor temperature was initially increased from room temperature to $600{ }^{\circ} \mathrm{C}$ with $10{ }^{\circ} \mathrm{C} / \mathrm{min}$ heating rate at a flow rate of $1 \mathrm{~L} / \mathrm{min}$ nitrogen gas. The final temperature of $600{ }^{\circ} \mathrm{C}$ was maintained for 1 -hour duration and the resulted activated carbon was denoted as A600-1. The aforementioned heating process (under the same heating temperature and rate) was also repeated for another three (3) different actyivated carbon samples each with different heating durations of 2, 3 and 4 hours. These three (3) activated carbons samples were designatd as A600-2, A600-3 and A600-4, respectively. After the activation process, all resulted activated carbons were washed with distilled water until the $\mathrm{pH}$ value of the washing effluent reached approximately 7; the samples were then dried at $105{ }^{\circ} \mathrm{C}$ overnight. After the drying process, the activated carbons were then ground and sieved with $75 \mu \mathrm{m}$ powder size sieve.

\subsection{Electrochemical characterization}

In order to characterize the activated carbon from kenaf-derived biochar, three pairs of identical working electrodes were prepared by mixing each activated carbon with polyvinylidene fluoride (PVDF) (Sigma-Aldrich, USA) as the binder agent and carbon black (C.nergy super C65, Imerys, Belgium) as the conductive agent in a mass ratio of 80:10:10 in N-Methyl-2-pyrrolidone. The resulting slurry was then coated to a nickel foam substrate that acts as the current collector and dried at $105{ }^{\circ} \mathrm{C}$ for 12 hours. The dried activated carbon electrodes were then pressed using a hydraulic press with 3-ton mechanical pressure. A symmetrical supercapacitor test cell consisting of two electrodes and an aqueous electrolyte of $1 \mathrm{M}$ sulfuric acid $\left(\mathrm{H}_{2} \mathrm{SO}_{4}\right)$ between the electrodes separated by $30 \mu \mathrm{m}$ thick cellulose paper was constructed to study the electrochemical properties of the activated carbon from the kenaf fibre.

Cyclic voltammetry (CV), galvanostatic load-discharge (GCD) and electrochemical impedance spectroscopy tests were carried out on each supercapacitor to examine the electrochemical properties of the electrodes. Both $\mathrm{CV}$ and GCD tests were performed within 0 to $1 \mathrm{~V}$ voltage window, which is the maximum 
voltage window for an aqueous $\mathrm{H}_{2} \mathrm{SO}_{4}$ electrolyte [26, 27]. The $\mathrm{CV}$ tests were analysed at different scan rates ranging from 2 to $10 \mathrm{mV} / \mathrm{s}$. The GCD measurements were tested at current density of $5 \mathrm{~mA}$. The specific capacitance $\left(C_{s}\right)$ of each constructed capacitor was calculated from the slope of the GCD's discharge curve [9]. Electrochemical impedance of each constructed supercapacitor was measured using an electrochemical measuring instrument, Gamry Interface1000 within a frequency range of $10 \mathrm{mHz}$ to 100 $\mathrm{kHz}$. All tests were carried out at room temperature condition under atmospheric pressure.

\section{RESULTS AND DISCUSSION}

\subsection{Electrochemical characterization}

\subsubsection{Cyclic voltammetry}

Figure 1 shows the cyclic voltammograms of the constructed supercapacitors with kenaf-derived activated carbon electrode at 2, 5 and $10 \mathrm{mV} / \mathrm{s}$. Referring to Figure 1(b)-(d), all the supercapacitors' performance exhibited a near rectangular shape except for A600-1 (Figure 1(a)). The rectangular shape of $\mathrm{CV}$ curves is not seriously distorted, even at higher scan rates. Even at faster scan rates of $10 \mathrm{mV} / \mathrm{s}$, the $\mathrm{CV}$ shape exhibits a near quasi-rectangular shape. This proves that there is less concentration polarization within the pores due to ion transport limitations, implying the kenaf-derived carbon electrodes are suitable for aqueous electrolytes $[11,28,29]$. At scan rates of $10 \mathrm{mV} / \mathrm{s}$ for A600-3, the $\mathrm{CV}$ shape is larger as compared to A600-1, A600-2 and A600-4 curves, which implies that the highest capacitance effect belongs to the supercapacitor with A600-3 electrodes. The CV curves of the activated carbon electrodes heated at different treatment durations obtained at $2 \mathrm{mV} / \mathrm{s}$ are presented in Figure 1(e). The static specific capacitance $C_{s, c v}$ of the constructed supercapacitors $[\mathrm{F} / \mathrm{g}]$ was accurately computed from the total voltammetry charge (during charge and discharge processes) [30,31]. The $C_{s, c v}$ value of each constructed supercapacitor is tabulated in Table 1. As expected, the supercapacitor with kenaf-derived carbon activated for 3 hours (A600-3) gave the highest specific capacitance of $181 \mathrm{~F} / \mathrm{g}$, followed by A600-2, A600-4 and A600-1 with 164 F/g, 122F/g and $90 \mathrm{~F} / \mathrm{g}$, respectively. In addition, as observed in Figure 1(f), the specific capacitance for each supercapacitor decreases as the scan rate increases. The typical trend of decreasing capacitance effect observed when increasing the scan rate implies the lack of time for ions to diffuse into the inner surface of electrode [27].

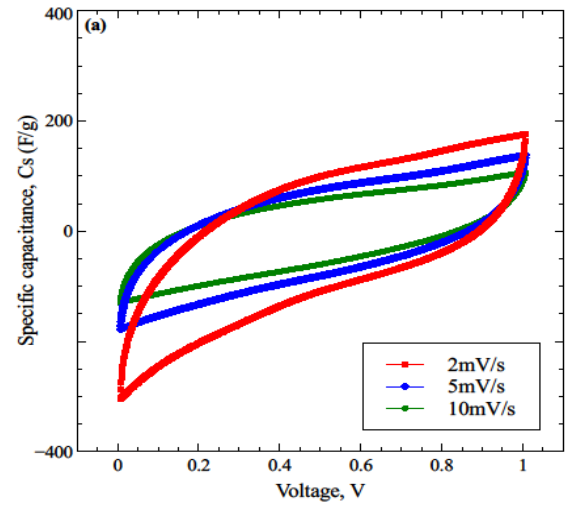

(a) CV of KFAC at 1 hour (A600-1)

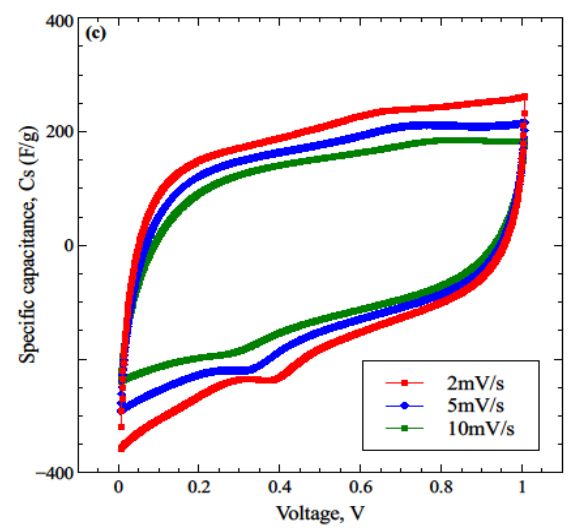

(c) CV of KFAC at 3 hours (A600-3)

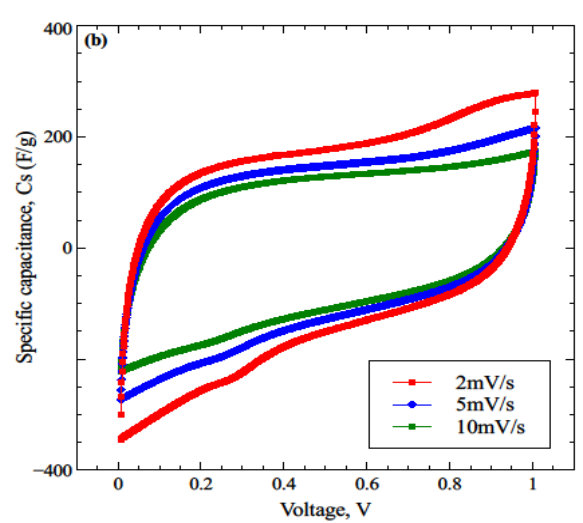

(b) CV of KFAC at 2 hours (A600-2)

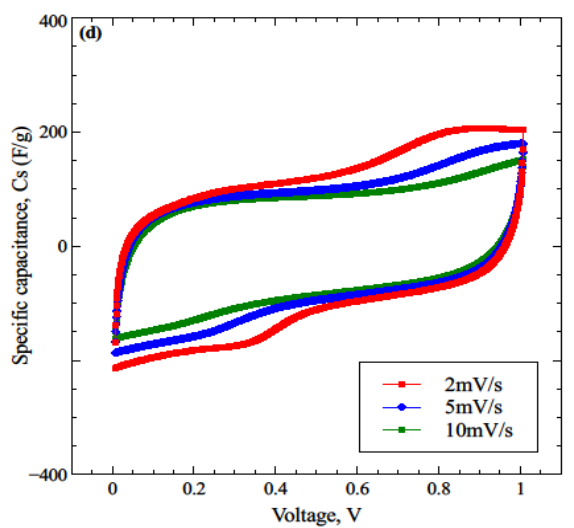

(d) CV of KFAC at 4 hours (A600-4) 


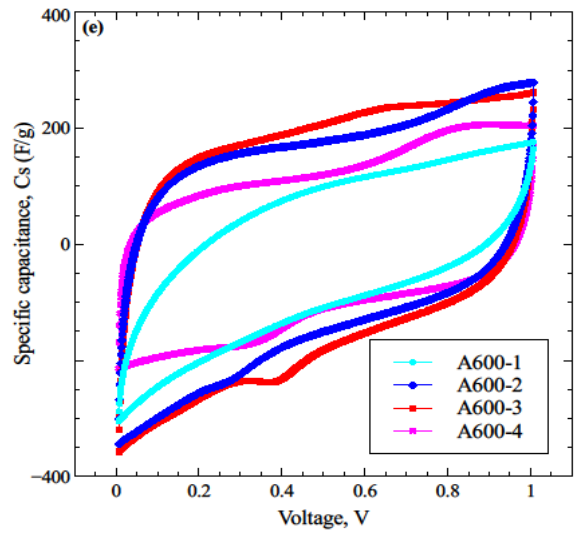

(e) CV comparison of all supercapacitors at $2 \mathrm{mV} \mathrm{s}^{-1}$

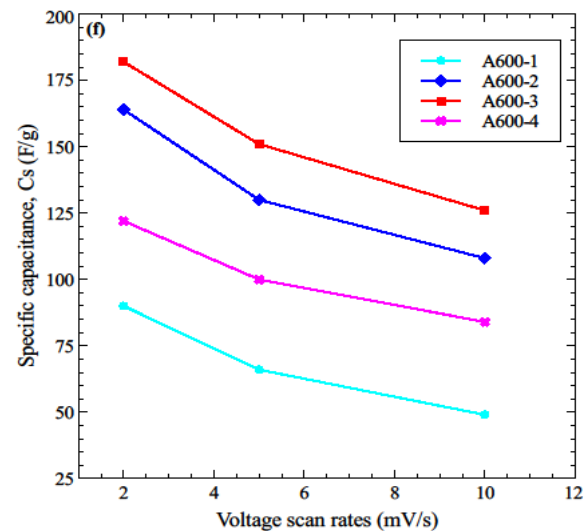

(f) Static specific capacitance versus scan rates

Figure 1. The cyclic voltammograms of the constructed supercapacitors with kenaf-derived activated carbon electrode at 2, 5 and $10 \mathrm{mV} / \mathrm{s}$

Table 1. Estimated specific capacitance, equivalent series resistance, electrolyte-electrode resistance,

\begin{tabular}{ccccc}
\multicolumn{5}{c}{ power density, and energy density values of the KFAC } \\
\hline & $\mathrm{A} 600-1$ & $\mathrm{~A} 600-2$ & $\mathrm{~A} 600-3$ & $\mathrm{~A} 600-4$ \\
\hline$C_{s, c v}$ at $2 \mathrm{mVs}^{-1}$ & 90 & 164 & 181 & 122 \\
$C_{s, g c d}$ at $5 \mathrm{~mA}$ & 108 & 189 & 242 & 126 \\
$R_{\text {ess, }, \text { sc }}$ & 2.98 & 2.19 & 2.24 & 1.63 \\
$R_{\text {ess,eis }}$ & 1.50 & 0.92 & 1.20 & 0.77 \\
$R_{\text {el,eis }}$ & 0.9 & 0.5 & 0.6 & 0.45 \\
$P(\mathrm{~W} / \mathrm{kg})$ & 916 & 2292 & 1892 & 2640 \\
$E(\mathrm{Wh} / \mathrm{kg})$ & 3.77 & 6.31 & 8.40 & 4.377 \\
\hline
\end{tabular}

\subsubsection{Galvanostatic charge-discharge}

Figure 2 shows the voltage responses of the constructed supercapacitors at $5 \mathrm{~mA}$ constant current obtained from GCD measurement. Referring to the figure, the curve profile for all supercapacitors clearly indicates typical capacitor behavior of electric double layer capacitance effect without any plateaus [10, 30]. The supercapacitor with A600-3 electrode exhibited longer charging and discharging time compared to others. The specific capacitance, $C_{s, g c d}$ values from GCD test are tabulated in Table 1. It can be seen in the table that the specific capacitances for the supercapacitors with A600-1, A600-2, A600-3, and A600-4 electrode are 108 F/g, $189 \mathrm{~F} / \mathrm{g}, 242 \mathrm{~F} / \mathrm{g}$ and $126 \mathrm{~F} / \mathrm{g}$ at $5 \mathrm{~mA}$, respectively. Interestingly, the specific capacitance recorded in this work is significantly higher than that of previously reported finding (37 F/g) with similar material [32]. These results are also in good agreement with the CV curves where the supercapacitor with A600-3 possesses longer discharge time, corresponding to higher capacity than the other supercapacitors.

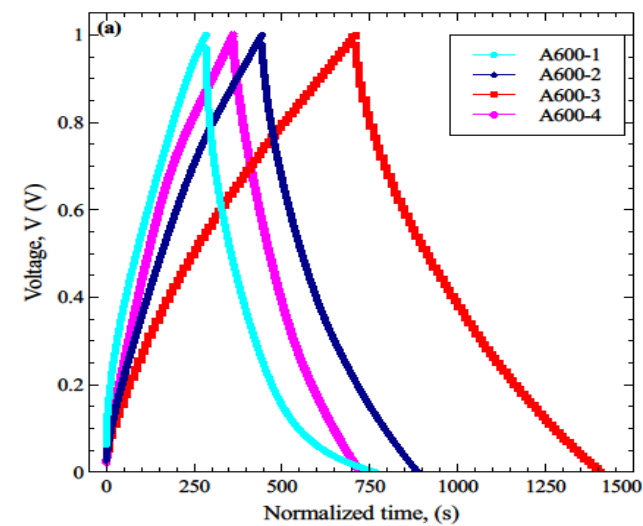

(a)

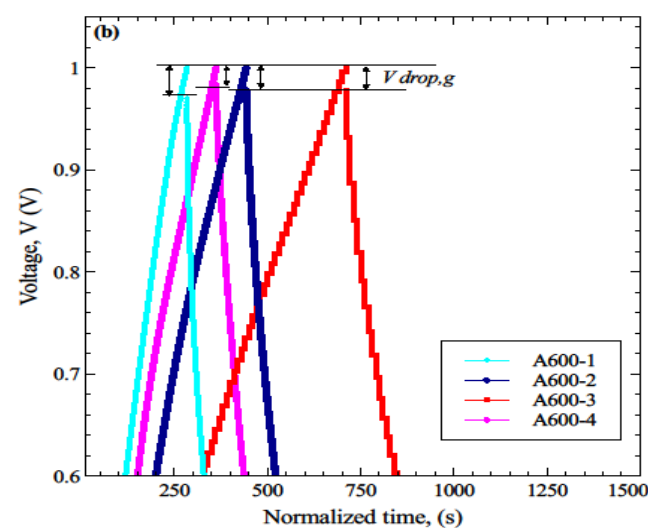

(b)

Figure 2. (a) Galvanostatic response of constructed supercapacitors at $5 \mathrm{~mA}$ constant charge-discharge current, (b) $V_{\text {drop }}$ for each of the KFAC 
As can be observed in Figure 2(b), voltage drop $\left(V_{\text {drop }}\right)$ appears at the instance of charge-discharge transition process which corresponds to the equivalent series resistance, $R_{\text {esr }, g c d}(\Omega)$ of the constructed supercapacitors. According to the data in Table 1, $R_{e s r, g c d}$ for supercapacitors with A600-1, A600-2, A600-3 and A600-4 electrodes are 2.98, 2.19, 2.24 and $1.63 \Omega$ respectively. Lower $R_{\text {esr }, g c d}$ at high heating temperature implies the pore widening phenomena during the heating process leading to the formation of more mesopores thereby increasing the mobility of the electrolyte ions within the pores of the electrodes [33].

\subsubsection{Electrochemical impedance spectroscopy}

The Nyquist plot of the constructed supercapacitors are shown in Figure 3. The steep slope in the low frequency region indicates decent electric double layer capacitance effect. The short $45^{\circ}$ slope in the medium frequency area reflects the Warburg impedance within the designed supercapacity which contributes to the diffusion of ions in the electrode materials' porous channels. In the high frequency region, a semicircle is observed, where its diameter corresponds to the charge transfer resistance $\left(R_{\text {esr,eis }}\right)$ at the electrode/electrolyte interface. The $\mathrm{Z}^{\prime}$-axis intercept at high frequency refers to the accumulation of the current collector-electrode contact resistance and the ohmic resistance of the electrode-electrolyte interface, termed $R_{e l}[26,30,34]$.

The recorded $R_{e l}$ values are $0.9,0.5,0.6$ and $0.45 \Omega$ for supercapacitors with A600-1, A600-2, A600-3 and A600-4 electrodes, respectively. The diameter of the semicircle curve in the high to medium frequency area corresponds to (i) the passive layer of the nickel foam current collector and (ii) the transfer resistance $\left(R_{e s r}\right)$ from the surface functionality of AC surfaces and the capacity of the double layer [34]. It is observed that the semicircle diameter for supercapacitors with A600-1 electrodes is larger than of A600-2, A600-3 and A600-4 as shown in Figure 3(b). The $R_{e s r}$ values for A600-1, A600-2, A600-3 and A600-4 are $1.5,0.92,1.2$ and $0.77 \Omega$ respectively.

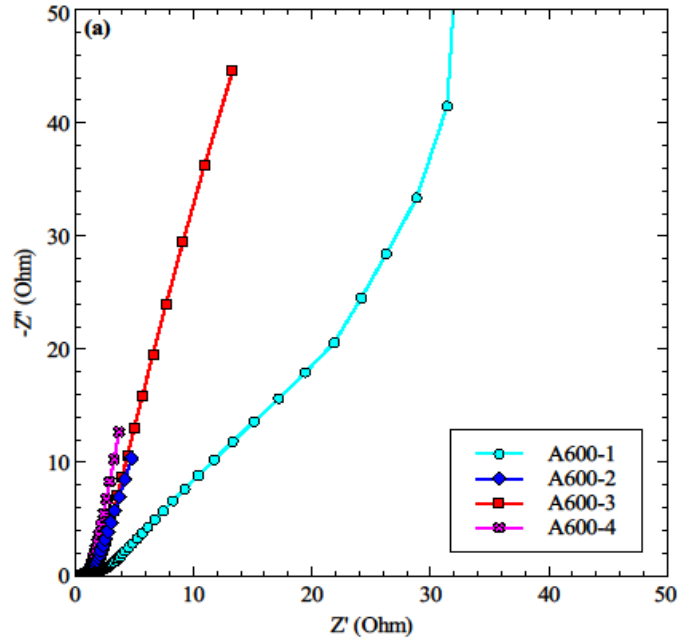

(a)

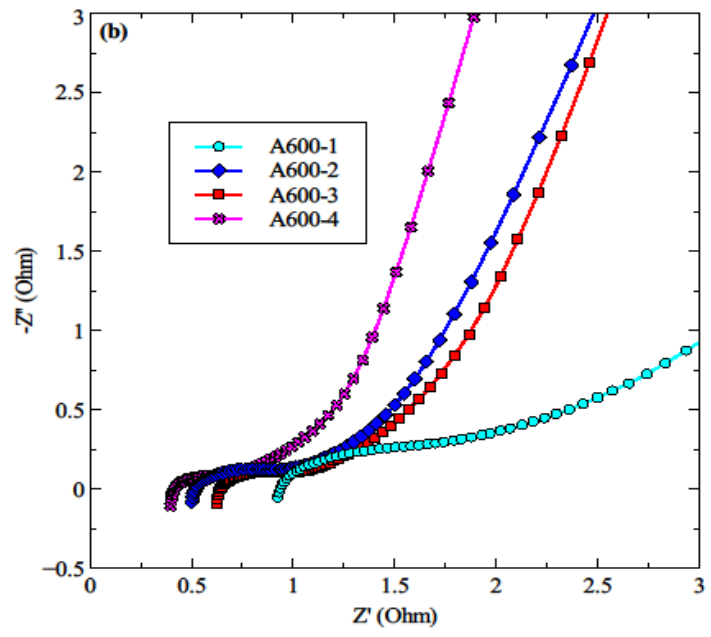

(b)

Figure 3. (a) Nyquist plot of impedance data from EIS measurement and its (b) close-up view in the high frequency region

\subsubsection{Power and energy densities}

As tabulated in Table 1, data obtained from GCD was used to calculate the power and energy density of each constructed supercapacitor. Referring to Table 1, the supercapacitor with A600-1 electrode has the lowest power and energy densities compared to other supercapacitors due to its high $R_{\text {esr.gcd }}$ value. Based on the Ragone plot in Figure 4, it shows that supercapacitor with kenaf-derived activated carbon treated for 3 hours heating activation time duration (A600-3) outperforms others in terms of its energy density. 


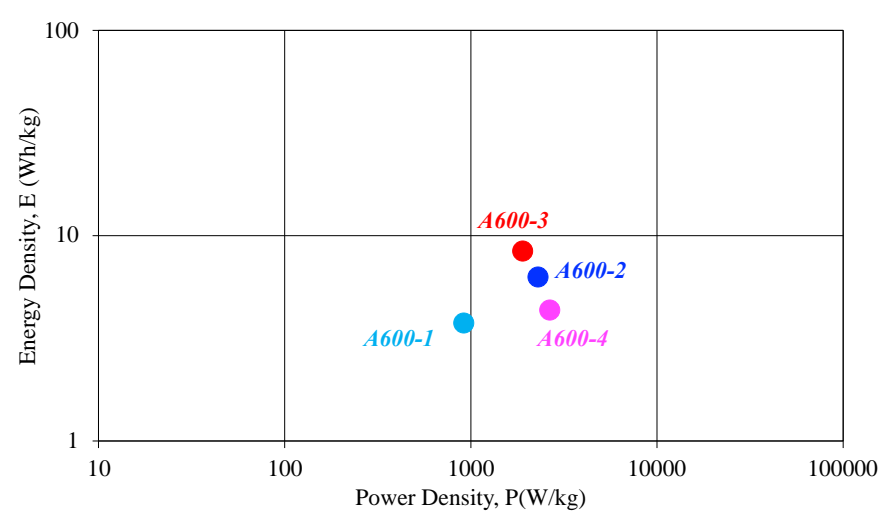

Figure 4. Ragone plot for all supercapacitors

\section{CONCLUSION}

This study aims to determine the optimum activation time required that contributes to highest supercapacitor's performance using kenaf-derived activated carbon electrodes. Supercapacitors with the kenaf-derived activated carbon electrodes were evaluated in terms of electrochemical properties. It was found that, the kenaf-derived activated electrode with the activation time duration of 3 hours (A600-3) gave an outstanding specific capacitance of $242 \mathrm{~F} / \mathrm{g}$, as well as superior energy density of $8.40 \mathrm{Wh} / \mathrm{kg}$ as compared to supercapacitors that were activated with a time duration of 1, 2 and 4 hours (A600-1, A600-2 and A600-4). Interestingly, this superior capacitance value in this work has outperformed similar previously reported work, utilizing kenaf as the activated carbon electrode with only $37 \mathrm{~F} / \mathrm{g}$ value. In general, this finding has proved that with proper activation process, kenaf can be one of the potential alternative candidates to be utilized as precursor material in supercapacitors' electrode construction. Systematic investigation is necessary in nearest future to further improve its electrochemical performance, for example in determining its optimum activation time duration and temperature.

\section{ACKNOWLEDGEMENTS}

The authors acknowledge the financial support from Universiti Teknologi Malaysia (Q.J130000.2523.18H04 \& Q.J130000.2509.18H10).

\section{REFERENCES}

[1] Ž. Kavaliauskas, L. Pranevičius, L. Marcinauskas, and P. Valatkevičius, "Deposition of carbon electrodes for supercapacitors using atmospheric plasma torch," Medziagotyra, 2009.

[2] X. Song, X. Ma, Y. Li, L. Ding, and R. Jiang, "Tea waste derived microporous active carbon with enhanced double-layer supercapacitor behaviors," Appl. Surf. Sci., 2019.

[3] K. Okajima, K. Ohta, and M. Sudoh, "Capacitance behavior of activated carbon fibers with oxygen-plasma treatment," Electrochim. Acta, 2005.

[4] S. S. Balaji and M. Sathish, "Supercritical fluid processing of nitric acid treated nitrogen doped graphene with enhanced electrochemical supercapacitance," RSC Adv., 2014.

[5] H. Jia, S. Wang, J. Sun, K. Yin, X. Xie, and L. Sun, "Nitrogen-doped microporous carbon derived from a biomass waste-metasequoia cone for electrochemical capacitors," J. Alloys Compd., 2019.

[6] M. Karnan, K. Subramani, N. Sudhan, N. Ilayaraja, and M. Sathish, "Aloe vera Derived Activated High-SurfaceArea Carbon for Flexible and High-Energy Supercapacitors," ACS Appl. Mater. Interfaces, vol. 8, no. 51, pp. 35191-35202, 2016.

[7] A. González, E. Goikolea, J. A. Barrena, and R. Mysyk, "Review on supercapacitors: Technologies and materials," Renew. Sustain. Energy Rev., vol. 58, pp. 1189-1206, 2016.

[8] E. Frackowiak, "Carbon materials for supercapacitor application," Phys Chem Chem Phys, vol. 9, no. 15, pp. 1774-1785, 2007.

[9] D. Momodu et al., "Activated carbon derived from tree bark biomass with promising material properties for supercapacitors," J. Solid State Electrochem., vol. 21, no. 3, pp. 859-872, 2017.

[10] I. I. Misnon, N. K. M. Zain, and R. Jose, "Conversion of Oil Palm Kernel Shell Biomass to Activated Carbon for Supercapacitor Electrode Application," Waste and Biomass Valorization, vol. 0, no. 0, pp. 1-10, 2018.

[11] B. Liu et al., "Nitrogen-Doped Banana Peel-Derived Porous Carbon Foam as Binder-Free Electrode for Supercapacitors," Nanomaterials, 2016. 
[12] Y. Sun and P. A. Webley, "Preparation of activated carbons from corncob with large specific surface area by a variety of chemical activators and their application in gas storage," Chem. Eng. J., vol. 162, no. 3, pp. 883-892, 2010.

[13] Y. Zhou et al., "Biomass-derived nitrogen and oxygen co-doped hierarchical porous carbon for high performance symmetric supercapacitor," J. Solid State Chem., vol. 268, no. August, pp. 149-158, 2018.

[14] "[Supplemantary] Free-standing activated flax fabrics with tunable meso_micropore ratio for high-rate capacitance.

[15] M. Kwiatkowski, "Analysis of the microporous structure of the low-cost activated carbon fibres obtained from flax and jute cloth," J. Math. Chem., vol. 55, no. 10, pp. 1893-1902, 2017.

[16] J. Illingworth, P. T. Williams, and B. Rand, "Characterisation of biochar porosity from pyrolysis of biomass flax fibre,” J. Energy Inst., vol. 86, no. 2, pp. 63-70, 2013.

[17] S. Liu, L. Ge, S. Gao, L. Zhuang, Z. Zhu, and H. Wang, "Activated carbon derived from bio-waste hemp hurd and retted hemp hurd for CO2adsorption," Compos. Commun., vol. 5, no. July, pp. 27-30, 2017.

[18] P. T. Williams and A. R. Reed, "Development of activated carbon pore structure via physical and chemical activation of biomass fibre waste," Biomass and Bioenergy, vol. 30, no. 2, pp. 144-152, 2006.

[19] J. M. Rosas, J. Bedia, J. Rodríguez-Mirasol, and T. Cordero, "HEMP-derived activated carbon fibers by chemical activation with phosphoric acid," Fuel, vol. 88, no. 1, pp. 19-26, 2009.

[20] A. Macías-García, E. M. Cuerda-Correa, M. Olivares-Marín, A. Díaz-Paralejo, and M. Á. Díaz-Díez, "Development and characterization of carbon-honeycomb monoliths from kenaf natural fibers: A preliminary study," Ind. Crops Prod., vol. 35, no. 1, pp. 105-110, 2012.

[21] A. Macias-Garcia, M. A. Franco, M. A. Dominguez, J. M. Naharro, and V. Encinas-Sanchez, "Preparation, characterization and study of morphology of activated carbon fibers," Bol. del Grup. Esp. del carbon, no. 42, pp. 2-6, 2016.

[22] M. R. Othman, H. M. Akil, and J. Kim, "Carbonaceous Hibiscus cannabinus L. for treatment of oil- and metalcontaminated water,” Biochem. Eng. J., vol. 41, no. 2, pp. 171-174, 2008.

[23] L. Wang et al., "Three-Dimensional Macroporous Carbon/Fe3O4-Doped Porous Carbon Nanorods for HighPerformance Supercapacitor," ACS Sustain. Chem. Eng., vol. 4, no. 3, pp. 1531-1537, 2016.

[24] L. Wang et al., "Template-free synthesis of hierarchical porous carbon derived from low-cost biomass for highperformance supercapacitors," RSC Adv., vol. 4, no. 93, pp. 51072-51079, 2014.

[25] N. Saba, M. Jawaid, K. R. Hakeem, M. T. Paridah, A. Khalina, and O. Y. Alothman, "Potential of bioenergy production from industrial kenaf (Hibiscus cannabinus L.) based on Malaysian perspective," Renew. Sustain. Energy Rev., vol. 42, pp. 446-459, 2015.

[26] R. Kötz and M. Carlen, "Principles and applications of electrochemical capacitors," Electrochim. Acta, 2000.

[27] M. F. M. Yaacob, Z. A. Noorden, and J. J. Jamian, "Charge-discharge cyclability of ultracapacitor with glass wool separator under high concentrated sulfuric acid," in PECON 2016 - 2016 IEEE 6th International Conference on Power and Energy, Conference Proceeding, 2017.

[28] L. Qie et al., "Synthesis of functionalized 3D hierarchical porous carbon for high-performance supercapacitors," Energy Environ. Sci., 2013.

[29] R. Farma et al., "Preparation of highly porous binderless activated carbon electrodes from fibres of oil palm empty fruit bunches for application in supercapacitors," Bioresour. Technol., 2013.

[30] Z. A. Noorden, S. Sugawara, and S. Matsumoto, "Noncorrosive separator materials for electric double layer capacitor," IEEJ Trans. Electr. Electron. Eng., vol. 9, no. 3, pp. 235-240, 2014.

[31] W. Chen, Z. Fan, L. Gu, X. Bao, and C. Wang, "Enhanced capacitance of manganese oxide via confinement inside carbon nanotubes," Chem. Commun., 2010.

[32] D. Lei, K.-H. Song, X.-D. Li, H.-Y. Kim, and B.-S. Kim, "Nanostructured polyaniline/kenaf-derived 3D porous carbon materials with high cycle stability for supercapacitor electrodes," J. Mater. Sci., vol. 52, no. 4, pp. 2158-2168, 2017.

[33] S. Shiung, R. Keey, X. Yi, F. Nasir, and A. Jusoh, "International Biodeterioration \& Biodegradation Fruit waste as feedstock for recovery by pyrolysis technique," Int. Biodeterior. Biodegradation, vol. 113, pp. 325-333, 2016.

[34] R. A. Aziz, I. I. Misnon, K. F. Chong, M. M. Yusoff, and R. Jose, "Layered sodium titanate nanostructures as a new electrode for high energy density supercapacitors," Electrochim. Acta, 2013.

\section{BIOGRAPHIES OF AUTHORS}

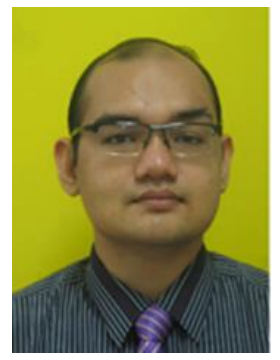

Muhammad Nizam Abdul Razak received the B. Eng degree from Universiti Malaysia Pahang (UMP) in 2013. He completed the M. Eng degree in electrical engineering from Universiti Teknologi Malaysia (UTM) in 2015. Currently, he is pursuing the Ph.D. degree at Universiti Teknologi Malaysia (UTM). His research interests include energy storage systems, power system dispatch and high-voltage generation. 

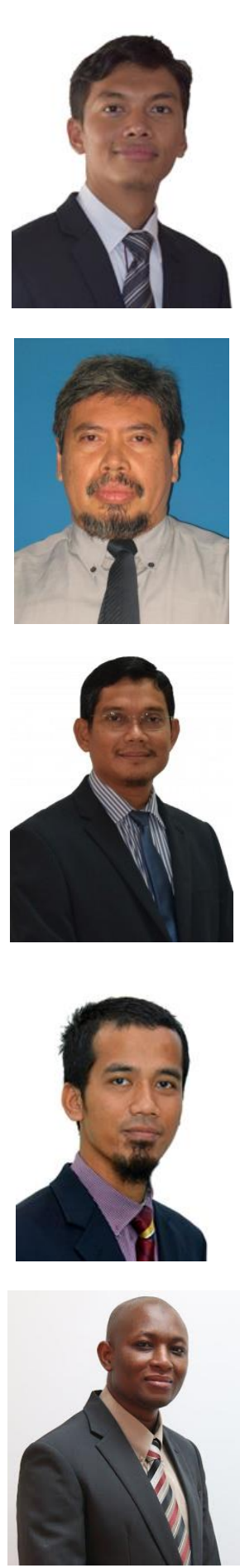

Zulkarnain Ahmad Noorden received the B.Eng. and M.Eng. degrees in Electrical Engineering from Universiti Teknologi Malaysia (UTM) in 2008 and 2009, respectively. In 2013, he completed his Ph.D. degree in Regional Environment System (Electrical Engineering) from Shibaura Institute of Technology, Tokyo, Japan. Currently, he is a Senior Lecturer at the Institute of High Voltage and High Current, UTM Johor Bahru, Malaysia. His research interests include ultracapacitor materials and technology, power equipment diagnosis, and high voltage generation.

Farid Nasir Ani graduated from University of Glasgow, Scotland, United Kingdom in Mechanical Engineering in 1982. His MSc (Eng) in 1985 at the University of Birmingham, United Kingdom in Thermodynamics and Related Studies. Later his PhD in 1992 from the University of Leeds, United Kingdom specialising in Fuel and Energy. He is currently a Research Professor at Faculty of Mechanical Engineering, Universiti Teknologi Malaysia, Skudai, Johor. His research interest renewable materials, activated carbon, biotechnology, coal, electromagnetic wave absorption, microwave heating, microwave materials, natural gas technology, particle size, renewable energy sources, sustainable development and thermochemistry.

Zulkurnain Abdul Malek obtained his B.E. from Monash University (Melbourne) in 1989 and his MSc and PhD degrees from University of Wales Cardiff in 1995 and 1999 respectively. Since 1989 he has been a member of the Electrical Engineering Faculty at Universiti Teknologi Malaysia (UTM). He is currently a Professor at the Institute of High Voltage and High Current, UTM. His research interests include high voltage systems, measurement techniques of fast currents and voltages, and fast transient response of high voltage surge arresters.

Jasrul Jamani Jamian received the B. Eng. (Hons) degree in electrical engineering in 2008, M. Eng. degree in Electrical Engineering (Power) in 2010 and Ph.D degree in Electrical Engineering (Power) in 2015 from Universiti Teknologi Malaysia (UTM), Johor Bahru, Malaysia. His current research interests include power system optimization, power system stability, and renewable energy applications and their control methods.

Nouruddeen Bashir Umar was born in Kano, Nigeria. He is a Senior Lecturer at Institute of High Voltage and High Current (IVAT), Faculty of Electrical Engineering, Universiti Teknologi Malaysia (UTM). He received the bachelors degree (B.Eng) in Electrical/Electronic Engineering from Abubakar Tafawa Balewa University (ATBU), Bauchi Nigeria. A masters degree (M.Eng) in Electrical Power and doctorate degree (Ph.D) in the area of High Voltage Engineering from Universiti Teknologi Malaysia in 2006 and 2009 respectively. He further received an MBA (Master of Business Administration) degree in 2014 from UTM International Business School. His research interests include, insulation condition monitoring of power system equipment, new insulating materials for high voltage application and renewable Energy. He is a Senior Member of IEEE and a Chartered Engineer. 